\author{
Ишмурадова И.И. ${ }^{1}$, Шагаипов Д.Р. ${ }^{1}$ \\ ${ }^{1}$ Набережночелнинский институт Казанского (Приволжского) федерального \\ университета
}

\title{
Реинжиниринг бизнес-процессов на предприятиях по выпуску хлебобулочных изделий
}

\begin{abstract}
АННОТАЦИЯ:
Данная статья посвящена вопросам реинжиниринга бизнес-процессов предприятия, которое занимается выпуском хлебобулочных изделий. Были рассмотрены основные пути повышения качества работы предприятия и средства их реализации. Итогом проведения реинжиниринга является возможность внедрения системы приема заявок на продукцию посредством мобильного приложения. Также в качестве примера рассмотрены несколько типов мобильных приложений и их основные возможности.
\end{abstract}

КЛЮЧЕВЫЕ СЛОВА: реинжиниринг бизнес-процессов, мобильное приложение, прием заказов, торговый представитель, информационные технологии, "Автоматизация бизнеса: Мобильная торговля», "Агент Плюс: Мобильная торговля», "VisitBasis»

JEL: M00, M10, M20

ДЛЯ ЦИТИРОВАНИЯ:

Ишмурадова И.И., Шагаипов Д.Р. Реинжиниринг бизнес-процессов на предприятиях по выпуску хлебобулочных изделий Экономика, предпринимательство и право. - 2016. 6(1). - с. 37-48. - doi: 10.18334/epp.6.1.35187

Ишмурадова Изида Илдаровна, магистр по направлению «Бизнес-информатика», старший преподаватель кафедры математических методов в экономике, Набережночелнинский институт Казанского (Приволжского) федерального университета (IIlshmuradova@kpfu.ru)

Шагаипов Динар Ривгатович, студент направления подготовки 010400.62 «Прикладная математика и информатика» кафедры математических методов в экономике, Набережночелнинский институт Казанского (Приволжского) федерального университета ПОСТУПИЛО В РЕДАКЦИЮ: 26.08.2015 / ОПУБЛИКОВАНО: 31.03.2016 ОТКРЫТЫЙ ДОСТУП: http://dx.doi.org/ 10.18334/ еpp.6.1.35187

(с) Ишмурадова И.И., Шагаипов Д.Р. / Публикация: ООО Издательство "Креативная экономика"

Статья распространяется по лицензии Creative Commons CC BY-NC-ND (http://creativecommons.org/licenses/by-nc-nd/3.0/)

ЯЗЫК ПУБЛИКАЦИИ: русский

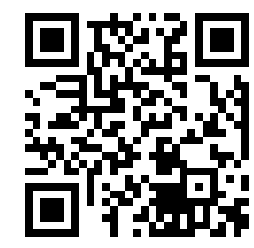




\section{Введение}

Среди множества способов коренного улучшения качества работы предприятия и роста эффективности ее деятельности в современных рыночных реалиях наиболее эффективным является реинжиниринг бизнес-процессов.

Под термином «реинжиниринг» понимается полное переосмысление, изменение и перепроектирование бизнес-процессов предприятия для получения заметных улучшений и изменений в особо важных показателях работы предприятия. «Бизнес-процесс - это множество связанных между собой видов деятельности, которое переводит входы предприятия в выходы, представляющие значимость для потребителя» [1].

Основы реинжиниринга были заложены Майклом Хаммером и Джеймсом Чампи в книге «Реинжиниринг корпорации: манифест для революции в бизнесе». Авторы дали термину «реинжиниринг» следующее определение: «фундаментальное переосмысление и радикальное перепроектирование бизнес-процессов для достижения существенных улучшений в таких существенных для современного предприятия показателях, как затраты, качество, уровень обслуживания и оперативность» [1].

В настоящее время работа любого предприятия состоит из множества различных бизнес-процессов. К ним можно отнести такие бизнес-процессы, как получение заявок от клиентов, осуществление доставки товаров, начисление зарплаты персоналу и т.д. Отсюда следует, что эффективность деятельности предприятия в огромной степени определяется эффективностью работы ее бизнес-процессов.

Целью реинжиниринга бизнес-процессов является улучшение отдельных направлений деятельности предприятия. «Реинжиниринг представляет собой целостное и системное моделирование и реорганизацию материальных, финансовых и прочих потоков, которые направлены на упрощение структуры предприятия, переосмысление использования ресурсов на предприятии, сокращение сроков выполнения задач и повышения их качества. Базируясь на определенных бизнес-процессах, создается система управления предприятием стандарт управления» [2].

Сутью реинжиниринга бизнес-процессов прежде всего является коренная перестройка работы предприятия. «В результате быстрого осуществления глубоких и разносторонних изменений компания 
достигает заметного, «прорывного» роста эффективности. В борьбе конкурирующих компаний побеждают те, кто может быть гибким, быстро и адекватно реагировать на изменения внешней среды, кто имеет отлаженную систему процессов разработки, производства, продажи, обслуживания своих товаров и услуг и поддержки работы с клиентами» [3].

Бизнес-процессы в реинжиниринге рассматриваются как система взаимосвязанных между собой задач, которые называют бизнесзадачами.

«Бизнес-задача - это часть бизнес-процесса, создающая базовый продукт. Внешние связи между бизнес-процессами рассматривается как связи задач, входящих в разные бизнес-процессы. В итоге продукт бизнес-процессов является продуктом решения задач» [4].

Отсюда следует, что в условиях современного рынка не обойтись без использования передовых технологий - производственных, управленческих, в том числе и реинжиниринга бизнес-процессов.

В данной статье рассмотрим организацию процесса реинжиниринга бизнес-процессов предприятия, которое занимается выпуском хлебобулочных изделий с доставкой готовой продукции в магазины, расположенные в разных частях города и за его пределами. Заказ продукции магазинами осуществляется на бумажном носителе. Эти заказы забирает торговый представитель пекарни, который затем предоставляет их в пекарню. После чего в пекарне по информации, полученной в заказе, производят выпуск необходимого ассортимента и количества продукции.

«Организационно-логическая сущность задач бизнес-процессов обычно отображается в виде схемы. На схеме изображены задачи и порядок их решения, причем эти задачи могут выполняться как одновременно, так и последовательно. Для отображения такой сущности можно использовать модель IDEF3, предназначенную для описания потоков работ. В диаграмме IDEF3 действие отображается с помощью прямоугольника. Имя задается с использованием глаголов или отглагольных существительных. Каждое действие имеет свой уникальный идентификационный номер, который затем нельзя использовать, даже если это действие удаляется. Связи предназначены для выделения существенных взаимоотношений между действиями и являются однонаправленными» [5]. 
Рассмотрим организационно-логическую сущность задач бизнеспроцесса «Выпуск хлебобулочных изделий». На первом этапе в пекарню поступает заявка от магазина. Затем происходит ее обработки бухгалтерией, после она передается в пекарню, где затем происходит подготовка производства. Если необходимые ингредиенты отсутствуют на складе, то они заказываются. Следующим шагом является выпуск продукции. Затем готовая продукция передается на склад, после чего она поступает заказчикам. Организационно-логическая сущность в виде схемы представлена на рисунке 1 [6].

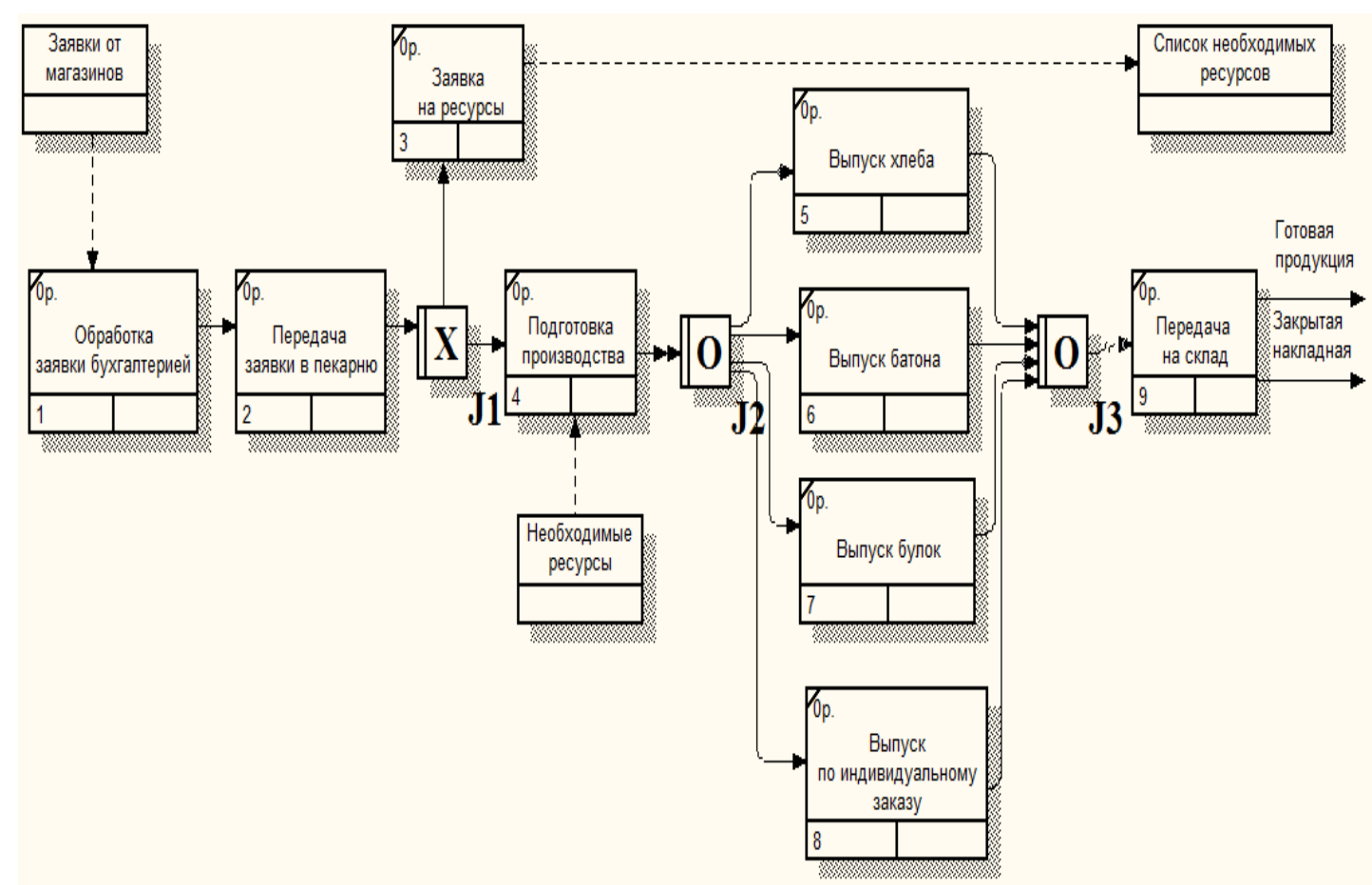

Рисунок 1. Организационно-логическая сущность бизнес-процесса «Выпуск хлебобулочных изделий»

Источник: составлено авторами

Однако любое предприятие не может постоянно работать по одной схеме. Совершенствуются технологии производства, хранения, доставки продукции, изменяются запросы и требования со стороны клиентов и поставщиков предприятия. Также свой вклад вносит конкуренция среди фирм. Все это приводит к выявлению различных 
факторов в деятельности предприятия, которые требуют пересмотра. Их пересмотр может привести к повышению качества работы предприятия.

При проведении анализа данного предприятия была выявлена необходимость переработки текущей деятельности и проведения реинжиниринга бизнес-процессов. Анализ показал, что сбор заявок на бумажном носителе сильно ограничивает возможности предприятия, так как без них предприятие не может начать выпуск продукции. Но во время их сбора торговыми представителями существует вероятность возникновения различных ситуаций, которые могут привести к срыву их доставки: поломка автомобиля, потеря заказов на бумажном носителе и т.д. Еще одной проблемой является невозможность редактирования заявок, которые уже переданы пекарне. Например, магазин хочет изменить количество продукции, который он заказал ранее или вовсе от него отказаться и т.д.

Все эти недостатки были учтены в плане по реинжинирингу бизнес-процессов данного предприятия.

После проведения реинжиниринга было принято решение отказаться от сбора торговыми представителями заявок на продукцию на бумажном носителе в пользу специального мобильного приложения, которое передавало бы информацию о заказе через сеть Интернет. Информация о заявке теперь также заносится в базу данных клиентов предприятия. Цепочка бизнес-процесса теперь выглядит следующим образом: заявка на продукцию поступает в пекарню в электронном виде. Затем она обрабатывается пекарней и происходит подготовка производства. После этого происходит выпуск продукции, которая потом упаковывается и поступает на склад, откуда она развозится по заказчикам.

Мобильное приложение дает огромные преимущества по времени обработки заявки. Заявка сразу поступает в пекарню через сеть Интернет, и теперь не нужно ждать, когда торговый представитель привезет ее от заказчиков, и только потом начинать подготовку производства [7].

Преимуществом мобильного приложения и электронной документации является не только сокращение времени обработки заявки, но и возможность уточнения, редактирования заявки или ее отмены. Также создание электронной базы данных о клиентах предприятия и их заявках позволяет облегчить работу сотрудников предприятия, например бухгалтеров, делает информацию о них более 
открытой и удобной для дальнейшего использования различными подразделениями предприятия.

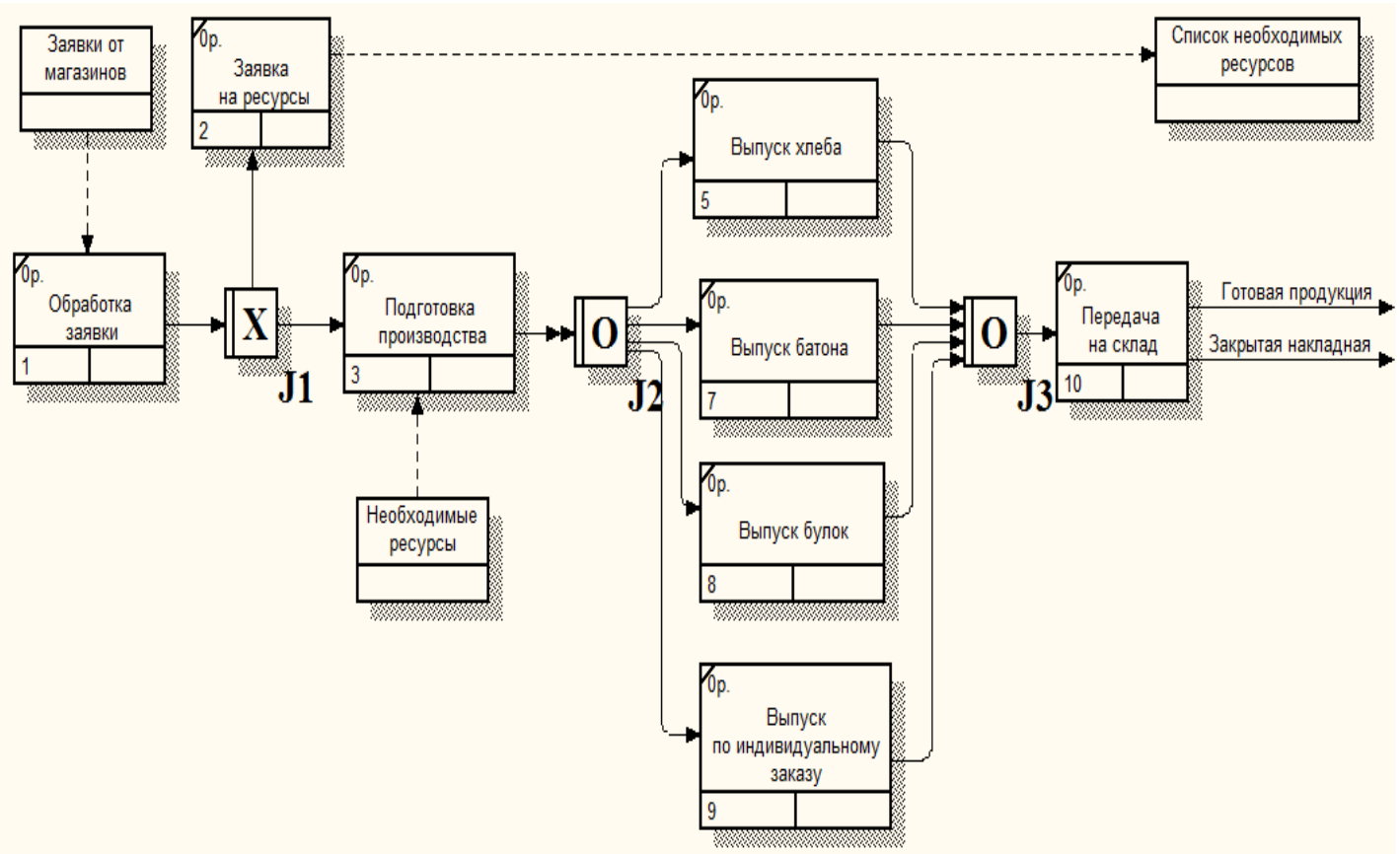

Рисунок 2. Модель IDEF3 бизнес-процесса «Выпуск хлебобулочных изделий» после реинжинига

Источник: составлено авторами

Реинжиниринг, проведенный на данном предприятии, позволил сократить время обработки заявки, сделал процесс ее получения более гибким и мобильным, повысил конкурентоспособность предприятия среди других фирм, позволил предприятию выйти на более современные параметры работы и осуществить потенциальные возможности повышения эффективности работы.

Сейчас на рынке мобильных приложений существует огромное количество приложений, предназначенных для ведения торговой деятельности. В качестве примера рассмотрим некоторые из них.

\section{Автоматизация бизнеса: Мобильная торговля}

«Автоматизация бизнеса: Мобильная торговля» - программный продукт, который позволяет быстро и качественно решать задачи по автоматизации работы торговых представителей. Данное приложение 
повышает эффективность продаж и рост качества исполнения заказов. Программа создана для использования на предприятиях, которые занимаются дистрибуцией товаров повседневного спроса [8].

Основные задачи, для решения которых предназначена программа:

1. Составление плана посещения предприятий и контроль его исполнения.

2. Сбор торговыми представителями заявок на точках и передача их в офис.

3. Отслеживание текущего состояния заявки.

4. Контроль работы торговых представителей.

5. Контроль времени движения по маршруту.

6. Контроль цен на товары, их остатков.

7. Получение информации об остатках на складе.

8. Работа с GPS для контроля местоположения торгового представителя.

9. Гибкая система ценообразования.

10. Отправка сообщений торговым представителям.

11. Возможность создания фотоотчетов [9].

Внедрение приложения позволяет:

1. Повысить эффективность продаж благодаря использованию информации об остатках на складах в текущий момент времени.

2. Повысить точность и скорость исполнения заказов.

3. Снизить расходы, связанные с работой торговых представителей.

4. Оценить эффективность каждого торгового представителя на основе его отчетов о созданных заявках и передвижениях.

5. Повысить имидж компании с помощью быстрого и качественного исполнения заказов.

\section{Агент Плюс: Мобильная торговля}

Данное мобильное приложение позволяет автоматизировать работу торговых представителей и мерчендайзеров. «Приложение работает на смартфонах и планшетах под управлением операционной системы Android. Также имеется возможность интеграции с различными корпоративными информационными системами» [10].

Автоматизация мобильной торговли позволяет:

- уменьшить транспортные расходы; 
- сократить штат сотрудников по вводу информации торговых представителей;

- оптимизировать остатки продукции на складе;

- увеличить объемы продаж.

Функциональные возможности приложения:

1) сбор, обработка заявок на товары: торговый представитель может быстро оформить заявку на поставку товаров;

2) учет взаиморасчетов: торговый представитель может следить за платежами и долгами каждого клиента предприятия;

3) общие и индивидуальные скидки: торговый представитель может работать с общими и индивидуальными скидками, предусмотренными для конкретного клиента;

4) онлайн и оффлайн контроль;

5) планирование посещения клиентов: торговый представитель может составить заранее маршрут посещений клиентов;

6) работа со сканерами штрих-кодов: в качестве сканера штрихкода можно использовать камеру мобильного телефона или сканер посредством Bluetooth-соединения;

7) детализация контактной информации клиентов: торговый представитель может использовать для работы любую информацию о клиенте: номер телефона, адрес и прочее;

8) обмен данными с основной учетной системой: торговый представитель может, не посещая офис, использовать беспроводной обмен данными с основной учетной системой, которая находится в офисе предприятия.

Конфигурируемость: возможность самостоятельно расширять или изменять функционал мобильного приложения без участия компанииразработчика.

В приложении «Агент Плюс: Мобильная торговля» реализована возможность двухстороннего обмена данными с помощью беспроводных технологий (GPRS, Wi-Fi и др.) с системой учета, которая установлена в офисе компании [10]. Перед началом своей работы торговый представитель производит обмен данными с системой учета, получая информацию об остатках товаров на складе, маршрутный лист на текущий день и приступает к работе. В течение дня торговый представитель оформляет в мобильном устройстве заказы на поставку товаров клиентам и отправляет их в центральную БД и периодически получает информацию об актуальных остатках. 


\section{VisitBasis}

VisitBasis - это мобильное решение для сбора данных. Облачное $\mathrm{SaaS}$ решение для смартфонов и планшетов, которое обеспечивает управление работой полевых команд, планирование и мониторинг их деятельности в режиме реального времени [11].

Данная программа предназначена для торговых представителей и обеспечивает возможность массового планирования визитов торговых представителей в точки продаж на любые временные периоды. Информация о запланированных посещениях хранится в смартфонах и планшетах торговых представителей.

C приложением для торговых представителей VisitBasis легко создавать задачи любой сложности с различными мультимедийными дополнениями, структурируя содержание визитов торговых представителей в точки продаж и определяя обязательные работы для каждого посещения: заказы и возвраты продукции, проверка цен, ассортимента, выкладка товара и многое другое.

Программное решение VisitBasis состоит из двух частей: Офисной для менеджеров и Мобильного приложения для торговых представителей. Приложение работает в онлайн и офлайн режимах.

Программа VisitBasis - единственное на рынке приложение для мобильной торговли, позволяющее бесплатно работать в полной версии сразу после регистрации. Подключение торговых представителей к системе занимает всего несколько минут.

Основные возможности приложения:

1. Фотоотчеты, аудит, фейсинг и т.д.

2. Планирование визитов и расписание.

3. Управление территорией и оптимизация маршрутов движения торговых представителей.

4. Электронный каталог продуктов, заказы и прайс-листы.

5. CRM.

6. Неограниченное число устройств для подключения.

7. Сбор всех данных в торговой точке.

8. GPS отслеживание и контроль времени.

9. Онлайн мониторинг активности мобильных агентов [12].

\section{Заключение}

В данной работе теоритические основы реинжиниринга бизнес процессов предприятия стали основой для проведения реинжиниринга 
деятельности предприятия, занимающиеся выпуском хлебобулочных изделий. Итогом данной работы стало использование специализированного мобильного приложения для торговых представителей, позволяющего отправлять заявки на продукцию с помощью сети Интернет.

\section{ИСТОЧНИКИ}

1. Хаммер М. Реинжиниринг корпорации: манифест для революции в бизнесе. - М.: Манн, Иванов и Фербер, 2011.

2. Чернявский Д.И. Моделирование и реинжиниринг бизнес-процессов. - Омск: Изд-во ОмГТУ, 2010.

3. Беккер Й., Вилков Л., Таратухин В. Менеджмент процессов. - М.: Эксмо, 2007.

4. Репин В.В., Елиферов В.Г. Процессный подход к управлению. Моделирование бизнеспроцессов. - М.: РИА «Стандарты и качество», 2004.

5. Ишмурадова И.И. Информационная инфраструктура предприятия как инструмент реализации системы менеджмента // Российское предпринимательство. 2014. - № 8 (254). - С. 83-88.

6. Романовский М.В., Белоглазова Г.Н. Экономика предприятия: Учебник. - М.: Высшее образование, 2006.

7. Чаадаев В.К. Бизнес-процессы в компаниях связи. - М.: Эко-Трендз, 2004.

8. Официальный сайт компании «Автоматизация бизнеса». URL: http://www.1cab.ru/.

9. Официальный сайт компании AB: MOBILE. Разработка мобильных приложений. URL: http://abmobile.ru/.

10. Официальный сайт Агент ПЛЮС. Решения для корпоративной мобильности. URL: http://www.agentplus.ru/company/.

11. Официальный сайт программы VisitBasis. URL: http://www.visitbasis.com/.

12. Русскоязычный сайт программы для торговых представителей VisitBasis. URL: http://программа-для-торговых-представителей.com/. 
Izida I. Ishmuradova, graduate student with specialization in "Business informatics", Senior Lecturer of the Chair of Mathematical Methods in Economics, Naberezhnye Chelny Institute of Kazan Federal University

Dinar R. Shagaipov, student with specialization 010400.62 "Applied Mathematics and Informatics" of the Chair of Mathematical Methods in Economics, Naberezhnye Chelny Institute of Kazan Federal University

\section{Re-engineering of business processes at bakery enterprises}

\section{ABSTRACT:}

This article is dedicated to the issues of re-engineering of business processes at bakery enterprises. The main ways to increase quality of an enterprise's work and methods for realization thereof have been considered in this article. Re-engineering results in the possibility to introduce the order taking system through a mobile application. Several types of mobile applications and their main possibilities have also been considered as an example.

KEYWORDS: re-engineering of business processes, mobile application, order taking, business representative, information technologies, "Business automation: Mobile Trade", "Agent Plus: Mobile Trade", "VisitBasis" 
